\title{
KEPRIBADIAN PENDIDIK DALAM PERSPEKTIF HADIS
}

\author{
Fahmi Sahlan \\ Dosen PAI, Universitas Bhayangkara Jakarta Raya \\ Email:fahmi.sahlan@dsn.ubharajaya.ac.id
}

\begin{abstract}
Abstrak
Sejalan dengan perkembangan dan tuntutan kebudayaan manusia, orang tua tidak dapat memenuhi kebutuhan pendidik anaknya. Untuk itu mereka menyerahkan pendidikan anaknya kepada orang lain. Orang yang menerima amanat orang tua untuk mendidik anak disebut guru. Profesi guru merupakan profesi mulia karena di samping menuntut ilmu seseorang, ia pun menuntut seseorang mempunyai akhlak yang mulia.

Nampaknya faktor terpenting dalam profesi guru sekarang ini adalah kualifikasi keilmuan dan akademis saja. Sedangkan faktor lain seperti kearifan dan kebijaksanaan yang merupakan sikap dan tingkah laku moral tidak lagi menjadi hal yang esensi. Akibatnya keteladanan moral para guru tidak lagi begitu penting dalm proses pendidikan, yang lebih utama adalah kecakapan dan keahlian dalam mengajar ilmu yang merupakan tugasnya.

Karena itu setiap orang yang akan melaksanakan tugas guru harus punya kepribadian yang sesuai dengan ajaran Islam dan lebih dituntut lagi untuk mempunyai kepribadian guru. Kepribadian merupakan faktor terpenting bagi seorang guru.
\end{abstract}

\begin{abstract}
In line with the development and demands of human culture, parents cannot meet the needs of their children's educators. For that they submit their child's education to others. People who accept the mandate of parents to educate children are called teachers. The teaching profession is a noble profession because in addition to studying one's knowledge, it also demands that someone have noble morals.

It seems that the most important factors in the teaching profession today are only scientific and academic qualifications. Meanwhile, other factors such as wisdom and wisdom which are moral attitudes and behaviors are no longer essential. As a result, the moral exemplary of the teachers is no longer so important in the educational process, what is more important is the skills and expertise in teaching science which is their duty.

Therefore, everyone who will carry out teacher duties must have a personality that is in accordance with Islamic teachings and is even more required to have a teacher personality. Personality is the most important factor for a teacher.
\end{abstract}




\section{Pendahuluan}

Sejalan dengan perkembangan dan tuntutan kebudayaan manusia, orang tua tidak dapat memenuhi kebutuhan pendidik anaknya. Untuk itu mereka menyerahkan pendidikan anaknya kepada orang lain. Orang yang menerima amanat orang tua untuk mendidik anak disebut guru. ${ }^{1}$ Guru sebagai pendidik professional telah merelakan dirinya menerima dan memikul tanggung jawab pendidik yang terikul di pundak orang tua. Oleh karena itu sebagai pemegang amanat yang berat sebagai guru harus bersungguh-sungguh dalam melaksanakan tugas dan tanggung jawab.

Profesi guru merupakan profesi mulia karena di samping menuntut ilmu seseorang, ia pun menuntut seseorang mempunyai akhlak yang mulia, segabaimana Azyumardi Azra mengatakan:

Citra dan konsep tentang guru dalam masyarakat kontemporer sangan jauh berbeda dengan konsep di masa lampau, bila dulu guru berarti orang yang berilmu yang arif bijaksana, kini guru dilihat tidak lebih sebagai fungsionaris pendidikan yang bertugas mengajar atas dasar kualifikasi keilmuan dan akademik tertentu. Untuk tugas ia memperoleh imbalan materi dari Negara atau pihak pengelola pendidikan lainnya. ${ }^{2}$

Nampaknya faktor terpenting dalam profesi guru sekarang ini adalah kualifikasi keilmuan dan akademis saja. Sedangkan faktor lain seperti kearifan dan kebijaksanaan yang merupakan sikap dan tingkah laku moral tidak lagi menjadi hal yang esensi. Akibatnya keteladanan moral para guru tidak lagi begitu penting dalm proses pendidikan, yang lebih utama adalah kecakapan dan keahlian dalam menajar ilmu yang merupakan tugasnya. Hal ini mengakibatkan kesulitan ank didik untuk merumuskan figur keteladanan dari guru. Padahal bagi anak didik terutama yang akan menginjak usia remaja dibutuhkan figure keteladanan, karena figure tersebut akan ditiru dan diikuti tingkah lakunya.

Karena itu setiap orang yang akan melaksanakan tugas guru harus punya kepribadian yang sesuai dengan ajaran Islam dan lebih dituntut lagi untuk mempunyai kepribadian guru. Kepribadian merupakan faktor terpenting bagi seorang guru, sebagaimana Imam Ghazali mengatakan:

\footnotetext{
1. Hery Noer Aly, Ilmu Pendidikan Islam., (Jakarta: Logos Wacana Ilmu, 1999), hlm. 93

2. Azyumardi Azra, Esai-Esai Intelektual dan Pendidikan Islam., (Jakarta: Logos Wacana Ilmu, 1998), hlm. 166
} 
Seorang guru mengamalkan ilmunya, kemudian perkataannya jangan membohongi perbuatannya. Karena sesungguhnya ilmu itu dapat dilihat dari kata hati, sedangkan perbuatan dapat dilihat dengan mata kepala, sedangkan yang mempunyai mata kepala adalah lebih banyak. ${ }^{3}$

Pernyataan Imam Ghazali tersebut menyatakan bahwa amal perbuatan, prilaku, akhlak dan kepribadian seorang guru adalah lebih penting dari ilmu yang dimilikinya, karena kepribadian seorang guru akan diteladani dan ditiru oleh anak didiknya baik secara langsung maupun tidak langsung.

Kepribadian seorang guru yang terwujud dalam sikap dan tingkah laku harus merujuk kepada diri Rasulullah Saw. sebagaimaan ayat al-Quran:

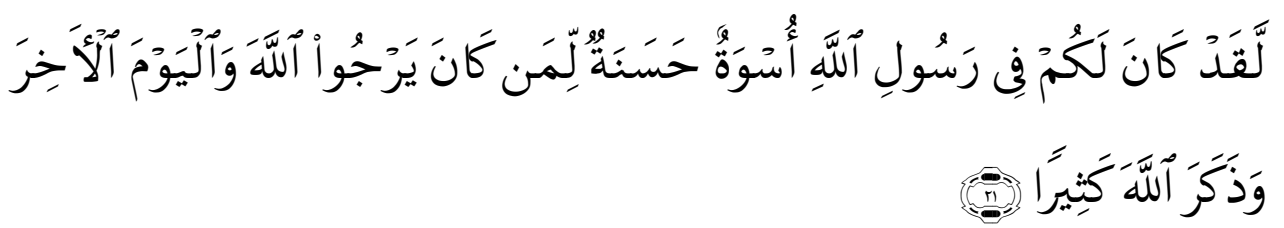

Sesungguhnya Telah ada pada (diri) Rasulullah itu suri teladan yang baik bagimu (yaitu) bagi orang yang mengharap (rahmat) Allah dan (kedatangan) hari kiamat dan dia banyak menyebut Allah. (Q.S. Al-Ahzab (33): 21)

Dari landasan ini, islam memandang bahwa guru bukan sekedar pengajar, namun ia sebagai pendidik sebagaimana tuntunan Rasulullah Saw. aktivitas pendidik bukan hanya mengandalkan keilmuan yang dimiliki seseorang, akan tetapi akhlak yang baik.

\section{Metodologi}

Dalam tulisan ini, penulis menggunakan metode deskriptif yang bertujuan untuk menggambarkan persoalan-persoalan teks hadis pendidik dalam proses belajar mengajar. Adapun objek penelitian adalah hadis pendidikan dan kepribadian pendidik.

\footnotetext{
3. Zainuddin dkk, Seluk Beluk Pendidikan dari Al-Ghazali., (Jakarta: Bumi Aksara, 1991), Cet. I, hlm. 56
} 


\section{Kepribadian Pendidik}

Secara Bahasa kepribadian disebut juga personality, dalam Bahasa latin personare yang berarti mengeluarkan suara. Istilah ini digunakan untuk menunjukan suara dari percakapan seseorang pemain sandiwara melalui topeng yang dipakainya. Pada mulanya istilah personare berarti topeng yang dipakai oleh pemain sandiwara. ${ }^{4}$

Secara terminologi, Zuhairini mengemukakan kepribadian adalah dinamis dari sistem spikofisik dalam individu yang turut menentukan cara-caranya yang unik (khas) dalam menyesuaikan dirinya dengan lingkungannya. ${ }^{5}$ Terbentuknya kepribadian disebakan banyak faktor, baik dari internal maupun eksternal. Perpaduan antara faktor dari internal dengan faktor eksternal menimbulkan gambaran yang unik, artinya tidak ada dua individu yang benar-benar identik antara seorang dengan lainnya.

Kepribadian dapat dirumuskan menajadi dua:

1. Kepribadian yang bersifat dinamis, artinya ia merupakan suatu totalitas psikofisik yang kompleks dari individu sehingga tampak dari tingkah laku yang unik.

2. Kepribadian yang menunjukan tingkah laku terintegrasi dan merupakan interaksi antara kesanggupan-kesanggupan bawaan yang ada pada individu dengan lingkungan.

Pendidik sebagai orang yang dewasa yang bertanggung jawab dan bertugas pendidikan dan pengajaran yang bertujuan membantu anak didik dalam mencapai kesempurnaan kepribadiannya. Oleh karena itu, kepribadian menjadi faktor terpenting yang akan menentukan apakah ia menjadi pendidik yang baik atau menjadi perusak bagi masa depan anak didik, karena tujuan umum pendidikan adalah membawa anak kepada kedewasaan yakni mampu menentukan diri sendiri dan bertanggung jawab sendiri. ${ }^{6}$

Dalam perspektif pendidik Islam, pendidik harus memiliki kepribadian sebagaimana imam Athiah al-Abrasy mengatakan, bahwa kepribadian yang harus dimiliki oleh pendidik adalah:

${ }^{4}$. Ngalim Purwanto, Psikologi Pendidikan, (Jakarta: Remaja Rosda Karya, 1999), Cet. IX, hlm. 154

5. Zuhairini, Filsafat Pendidikan Islam., (Surabaya: Al Maarif, 1995), Cet. II, hlm. 187

${ }^{6}$. Zakiah Darajat, Kepribadian Guru., (Jakarta: Biulan Bintang, 1978), hlm. 13 
1. Zuhud. Zuhud di sini diartikan adalah tidak mengutamakan materi dalam mendidik anak akan tetapi mencari keridhaan Allah, karena seorang pendidik mempunyai kedudukan yang tinggi dan mulia dan dia harus tahu kewajiban yang sesuai dengan posisinya. Sebagai pendidik, ia harus menjadi orang yang zuhud.

2. Bersih jasmani dan rohani, artinya seorang pendidik harus bersih tubuhnya, menjauhi diri dari dosa dan kesalahan serta menjauhi dari sifat-sifat tercela.

3. Sinkronisasi perkataan dan perbuatan

4. Bijaksana

5. Sabar, rendah hati, pemaaf, kasih sayang

6. Mengetahui karakter anak didik

7. Menguasai mata pelajaran. ${ }^{7}$

Namun menurut Imam Al-Ghazali bahwa kepribadian yang dimiliki oleh pendidik adalah:

1. Kasih sayang, artinya Menyayangi anak didik sebagaimana menyayangi anak sendiri,

2. Bertanggung jawab, artinya seorang pendidik tidak mengharapkan upah atau pujian, namun mengharapkan ridha Allah dan mendekatkan diri kepadaNya,

3. Selalu pemberi nasihat,

4. Selalu menegur tingkah laku anak didik,

5. Tidak fanatik

6. Memperhatikan fase anak didik agar menyampaikan ilmu sesuai dengan kemampuan berfikir anak didik,

7. Memperhatikan anak didik yang lemah,

8. Mengamalkan ilmu.

Menurut Imam Ghazali seorang pendidik jangan mencari bayaran dari pekerjaannya mengajar demi mengikuti jejar Rasul dengan alasan bahwa pekerjaan mengajar itu lebih tinggi harganya daripada harta benda, cukuplah kiranya seorang pendidik mendapatkan kebaikan dan pengakuan tentang

7. Armai Arief, Pengantar Ilmu dan Metodologi Pendidikan., (Jakarta: Ciputat Pers, 2002), Cet. I, hlm. 73 
kemampuan menunjukkan orang lain kepada jalan kebenaran dan hak, kebaikan dan ilmu pengetahuan, dan yang lebih utama lagi adalah pendidik menunjukan jalan yang hak kepada orang lain. ${ }^{8}$

Hal ini berbeda dengan pandangan Abu Hasan al-Qabisi, seorang ulama fiqih dan Sunnah, ia mengemukakan bahwa pekerjaan mendidik memerlukan ketekunan dan harus menanggalkan usaha lain untuk memenuhi tuntunan kehidupan, oleh karena itu maka sebaiknya kaum muslimin memberikan upah atau gaji kepada orang yang mau membaktikan dirinya untuk mengajar anak-anak secara rutin.

Melihat konteks sekarang, dua pendapat tersebut memiliki dasar pemikiran masing-masing, namun dilihat kecenderungan social sekarang penulis menganggap pendapat Abu Hasan al-Qabisi yang lebih relevan karena sifat ikhlas dan zuhud bukan mengajarkan pendidik untuk hidup miskin dan melarat, bukan berarti tidak boleh menerima upah atau gaji dari pekerjaan mengajar, mereka boleh menerima upah atau gaji tapi hendak bukan semata-mata karena materi tapi niat lah untuk mencari keridhaan Allah.

Pada dasarnya, kepribadian yang dituangkan dalam ajaran Rasul ketika mendidik adalah:

1. Ikhlas, yang dimaksud dengan ikhlas disini adalah pendidik dalam melaksanakan tugasnya didirong oleh niat yang tulus dan penuh tanggung jawab untuk mengabdikan diri kepada Allah melalui dunia pendidikan sehingga posisi upah atau gaji bukan menjadi prioritas utama dan dibolehkan untuk menerimanya.

2. Adil

3. Sabar

4. Tawakal, yang dimaksud tawakal atau berserah diri adalah ada sifat sadar dari pendidik bahwa tugasnya adalah menyampaikan namun keberhasilan dan kecerdasan peserta didik bukanlah merupakan kewajiban

5. Qan'ah.

\section{Kepribadian Pendidik Perspektif Hadis}

\footnotetext{
${ }^{8}$ Ali al-Jumbulati, Perbandingan Pendidikan Islam., (Jakarta: Rineka Cipta, 1994), Cet. I, hlm. 138
} 
Kepribadian pendidik yang diberikan oleh Rasul banyak sekali dalam hal pendidikan, dalah hal mengenai keteladanan mendidik dan membimbing anak di bidang akhlak, akidah, ibadah bahkan intelegensia. Rasul pernah bersabda:

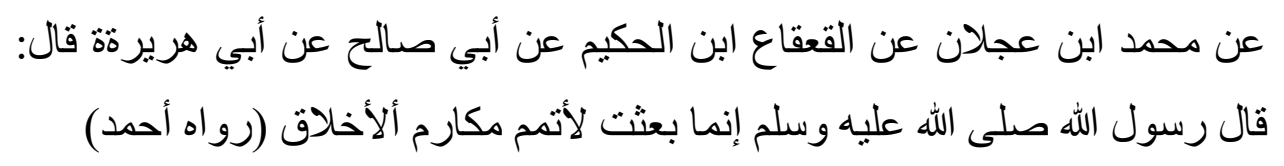

Dari Muhammad ibn 'Ijlan dari Qa'qa ibn Hakim dari Abi Shahih dari Abi hurairah ra. Berkata: Rasulullah saw. bersabda bahwasanya aku diutus ke dunia ini untuk menyempurnakan akhlak yang mulia (H.R. Ahmad)

Dari hadis di atas bahwa pendidik mengajari akhlak yang mulia serta menghindari dari perbuatan yang buruk. Akhlak peserta didik tergantung dari pendidikan yang diberikan oleh lingkungan mereka, baik di lingkungan keluarga yang terdiri dari orang tua, saudara, maupun lingkungan sekolah yang terdiri dari guru dan siswa, maupun juga di lingkungan masyarakat terdekat yaitu tetangga dan masyarakat luas.

Manakala mulai terlihat dalam diri anak akhlak yang baik dan perbuatan terpuji seperti menolong orang lain yangs edang kesulitan, hormat kepada guru, kasih sayang terhadap teman, berbuat baik dimana saja ia berada baik di lingkungan keluarga, sekolah, dan masyarakat maka sudah saatnya bagi orang tuanya untuk menghormatinya dengan memberinya penghargaan yang membuatnya senang dan makin terpacu untuk melakukannya lagi serta memujinya dihadapan orang lain.

Dengan demikian, vigur central berawal dari kepribadian pendidik sebagai bagian dari lingkungan sekolah sangatlah berpengaruh terhadap perkembangan anak, sehingga anak akan meniru dan mempraktekan apa yang ia dapat dari orang yang memberikan keteladanan akhlak terhadapnya.

Salah satu akhlak yang dimiliki dario pendidik adalah memiliki rasa sifat malu. Sifat malu disini dalam artian positif, yakni malu apabila melakukan perbuatan tercela, karena pendidik adalah sosok yang ditiru. Orang yang tidak memiliki rasa malu dalam melakukan perbuatan yang keji dan hina menunjukan kepribadian yang rapuh serta iman yang lemah, sebagaimana Rasul bersabda:

$$
\text { الحياء والإيمان قرنا جميعا فإذا رفع أحدهما رفع الآخر (رواه الحاكم) }
$$


Rasa Malu dan iman terpadu menajdi satu kesatuan, apabila lenyap salah satunya maka hilang pula yang lain. (H.R. Hakim)

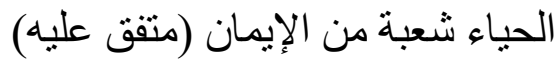

\section{Rasa malu adalah sebagian dari Iman (H.R. Bukhari dan Muslim)}

Rasa malu sangat berkaitan dengan iman sehingga dapat dikatakan tiaptiap orang yang beriman pastilah ia seorang pemalu dan tiap-tiap orang yang tidak punya rasa malu pastilah tidak ada iman di dalam jiwanya.

Seorang pendidik yang tidak malu melakukan tindakan amoral (melanggar ajaran agama), tidak terkontrol kepribadiannya, maka pendidik tersebut sesungguhnya belum siap untuk menjadi guru, ia akan mewariskan sifat-sifat negatif yang distruktif kepada anak didiknya dan hal itu akan sangat berbahaya bagi perkembangan jiwa peserta didik.

Seorang pendidik harus menjaga bicaranya dari perkataan keji, kotor, bertindak keras dan kasar yang dapat melukai hati dan fisik anak didik. Hal ini akan berimplikasi burukn dalam proses pembelajaran, karena seorang siswa tidak lagi menaruh simpati kepadanya malah yang ada adalah antipati dan kebencian kepadanya. Jika hal ini terjadi, maka sulit sekali tujuan pembelajaran dapat tercapai. Rasul pernah mengajarkan bahwa seorang yang beriman pasti menjaga perkataannya, sebagaimana sabdanya:

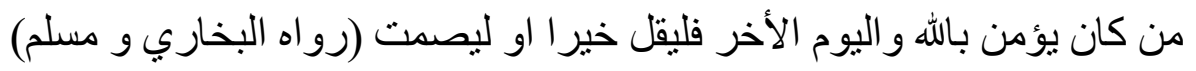

Barang siapa yang beriman kepada Allah dan hari kiamat, maka hendaklah berbicara dengan yang baik, kalau tidak hendaklah diam saja.

\section{(H.R. Bukhari dan Muslim)}

Dalam membina iman yang benar dan sempurna, Rasul terus menerus menanamkan akhlak yang mulia agar umatnya terpelihara dari perbuatan keji dan munkar. Pentingnya hubungan akhlak dengan iman dan hubungan iman dengan ibadah yang benar. Rasul menambahkan dengan menjadikan iman sebagai dasar segala kebaikan dan kebenaran di dunia serta keselamatan dan kebahagian di akhirat.

Pembinaan akhlak tidak kalah penting dari pembinaan yang lain. Oleh karena itu harus mendapatkan petunjuk dan nasihat yang terus menerus agar dapat meresap dalam hati dan melekat dalam ingatan hingga menjadi yakin bahwa iman, 
kebaikan dan akhlak adalah unsur yang erat kaitannya tidak bisa dipisahkan satu dengan yang lainnya.

Kepribadaian pendidik dalam perspektif Hadis bergungsi untuk menanamkan iman, ilmu, akhlak dan amal baik. Dengan demikian penyelenggaraan pendidikan diperlukan pendekatan yang tepoat dan strategis.

Pendekatan yang tepat dan strategis dalam pendidikan, yaitu: pertama, pendidikan dituntut untuk memiliki rasa kasih sayang kepada anak didik, sedangkan pendidik harus menyayangi peserta didik sebagaimana orang tua menyayangi anaknya. Apabila kasih sayang orang tua kepada anak adalah kasih sayang sepanjang hayat dan tanpa pamrih, maka kasih sayang seperti itu harus dimiliki oleh pendidik. Kedua, pendidikan yang harus sedini mungkin diberikan kepada anak didik adalah penanaman keimanan dan akidah yang benar. Ini menunjukan bahwa pendidikan kalbu anak didik dengan dasar-dasar percaya dan yakin kepada Allah harus lebih didahulukan dari pendidikan intelektrual dan keterampilan. Kenyataan membuktikan bahwa perkembangan dan kemajuan ilmu pengetahuan yang kering dari spiritualitas keimanan hanya menghasilkan kemajuan yang semu dan profan yang telah banyak melahirkan bentuk-bentuk peganisme baru berupa pemujaan kekuatan akal dan ilmu pengetahuan.

\section{Kesimpulan}

Kesimpulan dari penulis, bahwa pendidik merupakan orang dewasa yang bertanggung jawab memberi bimbingan atau bantuan kepada anak didik dalam perkembangan jasmani dan rohani agar dapat mencapai kedewasaannya, mampu melaksanakan tugasnya sebagai makhluk sekaligus khaligfah di bumi. Kepribadian pendidik dari perspektif hadis adalah kepribadian yang memiliki seluruh aspek-aspeknya, baik jasmani meliputi tingkah laku, maupun aspek rohani seprti cara berpikir dan minat. 


\section{Daftar Pustaka}

Aly, Hery Noer, Ilmu Pendidikan Islam., (Jakarta: Logos Wacana Ilmu, 1999)

Azra, Azyumardi, Esai-Esai Intelektual dan Pendidikan Islam., (Jakarta: Logos Wacana Ilmu, 1998), hlm. 166

Zainuddin dkk, Seluk Beluk Pendidikan dari Al-Ghazali., (Jakarta: Bumi Aksara, 1991), Cet. I, hlm. 56

Purwanto, Ngalim, Psikologi Pendidikan, (Jakarta: Remaja Rosda Karya, 1999), Cet. IX, hlm. 154

Zuhairini, Filsafat Pendidikan Islam., (Surabaya: Al Maarif, 1995), Cet. II, hlm. 187

Darajat, Zakiah, Kepribadian Guru., (Jakarta: Biulan Bintang, 1978), hlm. 13

Arief, Armai, Pengantar Ilmu dan Metodologi Pendidikan., (Jakarta: Ciputat Pers, 2002), Cet. I, hlm. 73

Al-Jumbulati Ali, Perbandingan Pendidikan Islam., (Jakarta: Rineka Cipta, 1994), Cet. I, hlm. 138

Hanafi, Hasan, Al-Yamin wa Al Yasar Fi Al-Fikr Al-Diniy, (Mesir: Madluby, 1989)

Hanafi, Hassan, min al-Aqidah ila al-Tsawrah al-Muqaddimat alNazhariyah, terjemah, Asep Usman Ismail, Dari Akidah Ke Revolusi, (Jakarta: Paramadina, 2003)

Hanafi, Hassan, Religious Dialougue \& Revolution, (Kairo: Anglo Egyptian Bookshop), ter. Tim Penerjemah Pustaka Firdaus Jakarta, 1991

Hanafi, Hassan, Dirâsah Islâmiyyah (Kairo: Maktabah Al-Anjilu alMishriyyah, 1981)

al-Farmawi, Abdul Hayy, Metode tafsir Maudhu'i., (Bandung: Pustaka Setia, 2002)

Zaid, Nasr Hamid Abu, Mafhūm al-Nash Dirāsah fì Ulūm al-Qurān., ter. Khoiron Nahdiyyin, Tekstualitas al-Qurān., (Yogyakarta: Lkis, 2002)

Zaid, Nashr Hamid Abu, Naqd al-Khithab al-Dini, (Kairo: Sina' li alNasrh, 1992) 